\title{
Native type II collagen-induced arthritis in the rat. III. Relationship between the cellular immune response to native type II collagen and arthritis
}

\author{
WILLIAM A. OFOSU-A PPIAH, KEITH MORGAN, ANDP. J. LENNOX HOLT \\ From the Department of Rheumatology, University of Manchester Medical School, Oxford Road, \\ Manchester M13 9PT
}

SUMMARY The relationship between cell mediated immunity to collagen and arthritis was studied with lymphocytes from arthritic and nonarthritic rats after immunisation with native bovine type II collagen. With the in-vivo radiometric ear assay arthritic rats gave a significantly higher response to native type II collagen than did nonarthritic rats. However, there was an overlap of values, and some arthritic rats gave no response to collagen even on the day of onset of arthritis. There was no difference in the response of lymphocytes from arthritic and nonarthritic rats with in-vitro transformation to native type II collagen, responses being found in both groups. All rats which developed arthritis had serum antibodies to native type II collagen, but not all responded to the tests for cell mediated immunity. These findings suggest that antibodies to collagen are more associated with the development of arthritis than is cell mediated immunity to collagen.

A model of inflammatory polyarthritis can be induced in rats ${ }^{1}$ and mice ${ }^{2}$ by intradermal immunisation with native type II collagen in Freund's adjuvant (complete or incomplete).

Cellular and humoral immune responses to native type II collagen are present in these rats after immunisation $^{3-5}$; the arthritis can be transferred to naive rats by cells ${ }^{6}$ or by antibody, ${ }^{7}$ and complement appears to play a role in the initiation of this arthritis. ${ }^{8}$ We have previously reported on the relationship of the humoral immune response to native type II collagen and the arthritis ${ }^{5}$ and here present our studies on the relationship of the cellular immune response and the arthritis.

\section{Materials and methods}

Rats. Outbred, female Sprague-Dawley rats $(150-250 \mathrm{~g})$ from the Manchester Medical School colony and male Alderley Park rats (Wistar derived; 250-300 g) were used. They were given food and water ad libitum.

Accepted for Publication 22 April 1982.

Correspondence to Dr. Keith Morgan, PhD, Department of Rheumatology, University of Manchester Medical School, Oxford Road, Manchester M1 3 9PT.
Collagen; Native bovine type II collagen was extracted from nasal septum cartilage by pepsin solubilisation after previous treatment with $2 \mathrm{M}$ magnesium chloride. ${ }^{10}$ Acid-soluble native type I collagen was extracted from fetal calf skin and purified by the method of Jackson and Cleary. ${ }^{11}$ Both collagens were lyophilised and stored at $-20^{\circ} \mathrm{C}$ in a desiccator until used. The collagen types appeared pure on polyacrylamide gel electrophoresis and the type II collagen was negative for uronic acid, suggesting that there was no proteoglycan contamination. ${ }^{12}$

For immunisation native type II collagen was dissolved in sterile $0.45 \mathrm{M} \mathrm{NaCl} / 0.02 \mathrm{M}$ Tris buffer, $\mathrm{pH}$ $7 \cdot 4$, at a concentration of $1 \mathrm{mg}$ per $\mathrm{ml}$ before use. Type I collagen was dissolved in sterile $0 \cdot 1 \mathrm{M}$ acetic acid at the same concentration and dialysed extensively into sterile $0.45 \mathrm{M} \mathrm{NaCl} / 0.02 \mathrm{M}$ Tris buffer.

For in-vitro studies both native type I and type II collagen were dissolved in sterile $0 \cdot 1 \mathrm{M}$ acetic acid and dialysed extensively into sterile $0.02 \mathrm{M}$ phosphate $/ 0 \cdot 14 \mathrm{M} \mathrm{NaCl}$ pH 7.2.

IMMUNISATION IN RATS

Native type II collagen $(1 \mathrm{mg} / \mathrm{ml})$ was emulsified in Freund's complete adjuvant (CFA) or Freund's incomplete adjuvant (ICFA) at a ratio of $1: 1$. Native type I collagen $(1 \mathrm{mg} / \mathrm{ml})$ was emulsified in CFA at 
the same ratio. Emulsions of $0.45 \mathrm{M} \mathrm{NaCl} / 0.02 \mathrm{M}$ Tris with either ICFA or CFA were also made.

Rats were injected intradermally on the back at several sites with a total of $1 \mathrm{ml}$ of emulsion containing $500 \mu \mathrm{g}$ of native type I or II collagen or buffer alone.

Rats were examined throughout the experiment for evidence of arthritis or nonarticular lesions. All rats were immunised and kept in the animal unit of the Manchester Medical School.

Blood was collected from rats under light ether anaesthesia by cardiac puncture. After clotting, the blood was centrifuged at $1500 \mathrm{~g}$ for 7 minutes and the serum removed and stored at $-20^{\circ} \mathrm{C}$.

IN-VITRO MONONUCLEAR CELL STIMULATION The inguinal, popliteal, axillary, and brachial lymph nodes were removed aseptically into $10 \mathrm{ml}$ of sterile Hanks balanced salt solution (HBSS) and gently teased out. The cell suspension was filtered through rough and then fine gauze before layering on $10 \mathrm{ml}$ of Ficoll/Hypaque gradient, ( $40 \mathrm{ml}$ of $14 \%$ Ficoll $/ 20 \mathrm{ml}$ of $45 \%$ Hypaque). The gradient was centrifuged at $1300 \mathrm{~g}$ for 20 minutes at $15^{\circ} \mathrm{C}$ and the resultant cell layer aspirated from the interface. The cells were washed once in HBSS, counted, tested for viability with flourescein diacetate, ${ }^{13}$ and resuspended at a concentration of $1 \times 10^{6}$ cells per $\mathrm{ml}$ in sterile Roswell Park Memorial Institute (RPMI) 1640 medium with $25 \mathrm{mM}$ Hepes, $100 \mu \mathrm{g}$ per $\mathrm{ml}$ penicillin and streptomycin and $20 \mathrm{mM}$ L-glutamine. Cytocentrifuge slides were prepared to check the content of the preparation. Routinely the cells were over $96 \%$ viable, and over $95 \%$ of the cells were lymphocytes.

Quadruplicate cultures of cells (final concentration $5 \times 10^{5}$ per $\mathrm{ml}$ ) were set up in sterile disposable tissue culture plates (Nunc UK Ltd) in RPMI 1640 medium with pooled, heat-inactivated, normal rat serum (Sprague-Dawley) added to a final concentration of $10 \%$ and with $5 \times 10^{-5} \mathrm{M} 2$-mercaptoethanol. The lymphocytes were cultured with either $0,10,20$, or $50 \mu \mathrm{g}$ of collagen at $37^{\circ} \mathrm{C}$ in $5 \% \mathrm{CO}_{2} / 95 \%$ air in a humidified incubator for 6 days (time of maximum response). For the last 6 hours of culture $10 \mu \mathrm{l}$ of a 10 $\mu \mathrm{Ci}$ per $\mathrm{ml}$ solution of 5 -iodo-2'-deoxyuridine- ${ }^{125} \mathrm{I}$ ( ${ }^{125}$ IUdR; Radiochemical Centre, Amersham) was added per well. The cells were aspirated on to glassfibre filters with a Skatron Cell Harvestor and flushed with distilled water. After drying, the filters were counted on an LKB Ultro gamma spectrometer.

For concanavalin-A responses the lymphocyte cultures were set up as above except that the cultures contained either $0,2,4,8$, or $10 \mu \mathrm{g}$ per $\mathrm{ml}$. of concanavalin-A ( 3 times crystallised con-A, Miles Laboratories Ltd) and were harvested after 4 days.

The results were expressed as a stimulation index (ratio of mean counts per minute of cells incubated with collagen divided by mean counts per minute of cells incubated with medium alone).

\section{RA DIOMETRIC EAR ASSAY}

The radiometric ear assay was based on the method of Gans et al. ${ }^{14} 50 \mu \mathrm{l}$ of the test $(1 \mathrm{mg} / \mathrm{ml}$ concentration) antigen was injected into the pinna of one ear of a rat and $50 \mu$ l of the buffer in which the antigen was dissolved was injected into the pinna of the opposite ear. After 6 hours $2 \mu \mathrm{Ci}(0.5 \mathrm{ml})$ of ${ }^{125} \mathrm{IUdR}$ was injected subcutaneously into the flank. After a further 18 hours the rats were killed and the pinnae were removed at the hairline. Blood was also taken at this time. The samples were counted on the LKB gamma spectrometer and the ratios of the counts per minute (cpm) of the antigen-injected ear to the cpm of the buffer-injected ear were calculated.

The antigen specificity of the elicited ear response was checked by challenging both native type I and native type II collagen sensitised rats with both native type I and native type II collagen; and by challenging both unsensitised rats and rat sensitised to buffer and adjuvant alone with native type II collagen.

\section{RA DIOIMMUNOASSAY}

Serum IgG antibodies to collagen were measured by an adaption of the assay described by Clague et al. ${ }^{15}$ Tween 20 to a concentration of $0.05 \%$ was added to all PBS solutions used for washing procedures to cut down the levels of nonspecific binding. Results were expressed as the amount of radioactively labelled anti-rat IgG bound by the collagen-specific antibodies in the rat sera.

\section{STA TISTICS}

The collagen stimulation index was compared with the con-A stimulation index by means of Pearson's correlation coefficient. The serum IgG levels to native bovine type II collagen were compared with both the collagen stimulation index and the con- $A$ stimulation index by the same parametric statistical test.

The ear index was compared between groups of rats by the Mann-Whitney $U$ test and compared with the serum IgG levels to native bovine type II collagen by Spearman's correlation coefficient. The latter 2 nonparametric tests were used as these data were not normally distributed.

\section{Results}

SPECIFICITY OF THE IN-VITRO MONONUCLEAR CELL STIMULATION BY NATIVE TYPE II COLLAGEN

From preliminary experiments with the lymphocytes separated from the lymph nodes of rats sensitised to 
native bovine type II collagen it was found that the maximum stimulation in vitro was obtained by incubating the cells for 6 days with $20 \mu \mathrm{g} / \mathrm{ml}$ of native bovine type II collagen whether the rats were arthritic or not. The specificity of this response was checked by the following experiments. The lymphocytes from 10 rats immunised 21 days previously with $0.45 \mathrm{M} \mathrm{NaCl} / 0.02 \mathrm{M}$ Tris buffer emulsified in ICFA (5 rats) or CFA (5 rats) gave stimulation indices (SIs) of less than 1.4 over the $0-50 \mu \mathrm{g} / \mathrm{ml}$ concentration range of native type II collagen, as did the lymphocytes from 5 normal unsensitised rats. When the lymphocytes from 5 rats sensitised 21 days previously with native type II collagen were challenged in vitro with native type II collagen the maximum SIs were between 1 and 10 (median 8), while the same lymphocytes challanged in vitro with native type I collagen all gave maximum SIs less than $1 \cdot 4$. Thus only rats immunised with native type II collagen had lymphocytes which gave an in-vitro response to native type II collagen with an SI above $1 \cdot 4$, and this response was not elicited by native type I collagen.

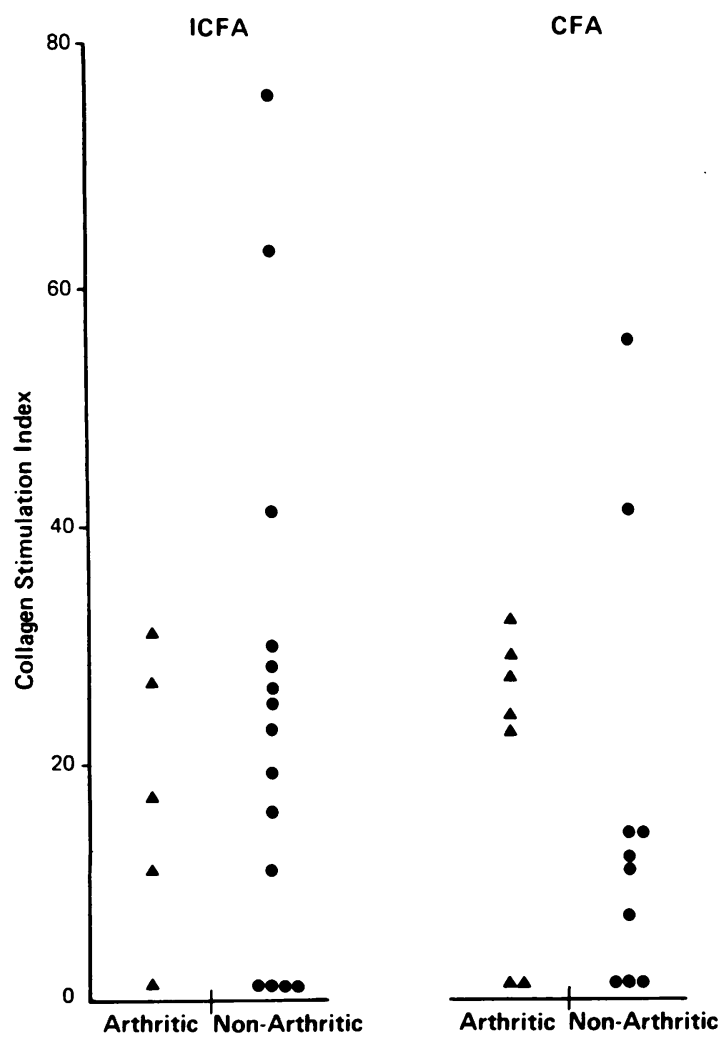

Fig. 1 Stimulation of lymphocytes in-vitro with native type II collagen, 20-30 days after immunisation.

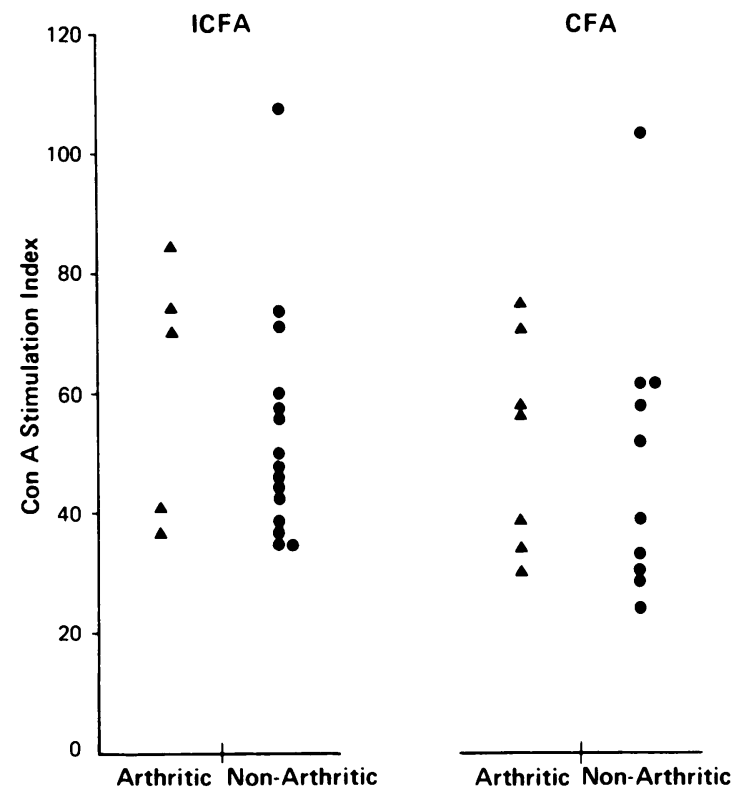

Fig. 2 Stimulation of lymphocytes in-vitro with concanavalin-A, 20-23 days after immunisation.

IN-VITRO RESPONSE TO NATIVE TYPE II COLLAGEN

The result for the following experiments are given for the maximum stimulation (produced by $20 \mu \mathrm{g} / \mathrm{ml}$ of native type II collagen), though the full range of collagen concentrations were used in each experiment.

Lymphocytes from 10 rats immunised with native type II collagen emulsified in ICFA and 6 rats immunised with native type II collagen in CFA were tested on day 11 after immunisation and before any clinical evidence of arthritis. Stimulation indices for these rats ranged from 8.5 to 23 for ICFA (median $15 \cdot 5$ ) and 3 to 15 for CFA rats (median 6.5).

In 20 rats immunised with native type II collagen +ICFA 20-23 days previously 5 (25\%) developed an inflammatory polyarthritis, and in 17 rats immunised at the same time with native type II collagen +CFA 7 (41\%) developed arthritis. The stimulation indices obtained from lymphocytes of these rats with in-vitro incubation with native type II collagen can be seen in Fig. 1. It should be noted that 3 arthritic rats had SIs less than 1.4 and that similar values were obtained with lymphocytes whether the rats were immunised with native type II collagen +ICFA or native type II collagen +CFA.

The responses to con-A of these same lymphocytes are shown in Fig. 2. All the stimulation indices were above 20 and all groups gave similar responses. 


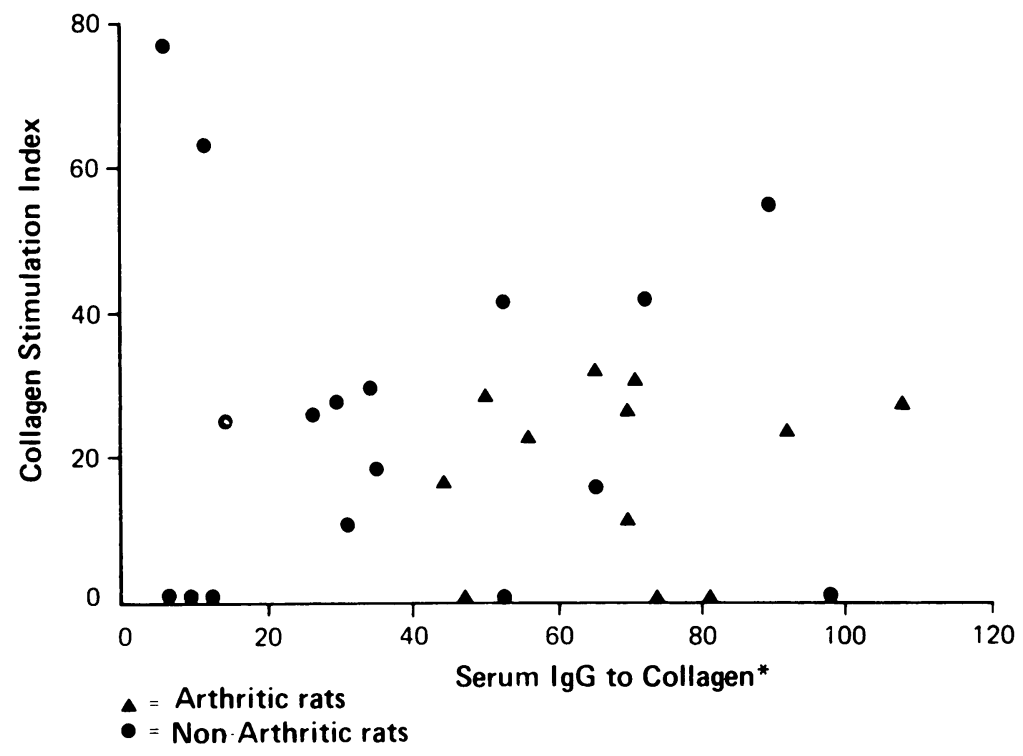

Fig. 3 Comparison of collagen stimulation index with levels of serum $\mathrm{IgG}$ to collagen in rats immunised with native type II collagen 20-23 days previously. ${ }^{*}$ Measured as $\mu \mathrm{g}$ of ${ }^{125}$ I-labelled anti-rat $\operatorname{Ig} G$ bound by anticollagen antibodies per ml of serum.

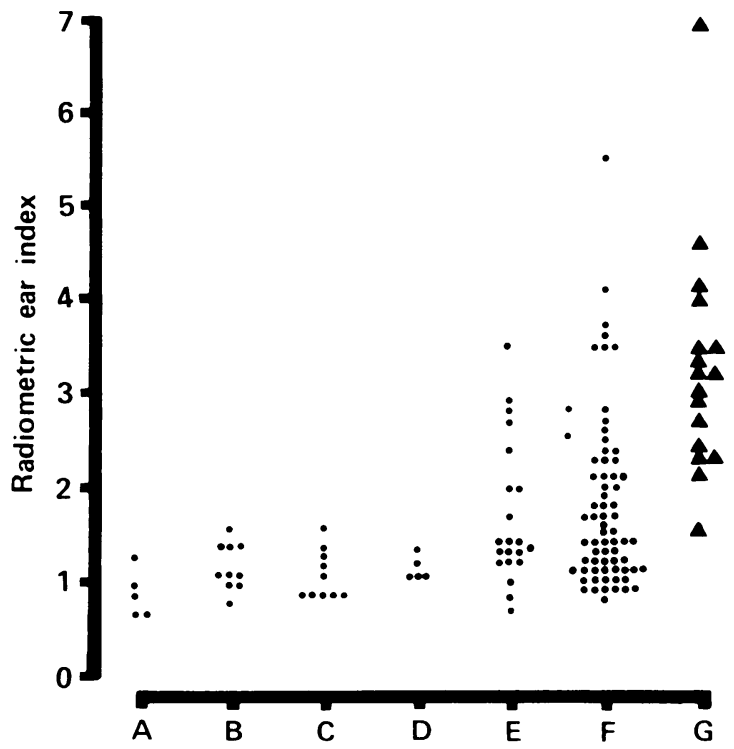

Fig. 4 Radiometric ear assay: levels in different groups of rats.

Key to Fig. 4

\begin{tabular}{lll}
\hline Group & Immunised with & Challenged with \\
\hline A & Unimmunised & Native type II collagen \\
B & ICFA + buffer & Native type II collagen \\
C & Native type II collagen \\
D & Native type II collagen + ICFA & Native type I collagen \\
E & Native type II collagen + ICFA & Native type II collagen - day 10 pre-arthritic \\
F & Native type II collagen + ICFA & Native type II collagen - day 21 non-arthritic \\
G & Native type II collagen + ICFA & Native type II collagen - day 21 arthritic \\
\hline
\end{tabular}

By the Pearson correlation coefficient there was no correlation between the collagen stimulation index and the con-A stimulation index whether the rats had been immunised with collagen in ICFA or CFA. Also there was no correlation between these measurements when arthritic rats were compared with nonarthritic rats.

IgG ANTI-COLLAGEN ANTIBODIES IN THESE R A T S

When the IgG antibodies to native type II collagen in the sera of these rats were measured 21 days after immunisation and compared with in-vitro lymphocyte stimulation by native type II collagen, there was no correlation by the Pearson correlation coefficient between these 2 values (Fig. 3). Similarly there was no correlation between the $\mathrm{IgG}$ antibodies to native type II collagen and the in-vitro response to con-A. It should be noted that all arthritic rats had antibodies to native type II collagen in their sera.

RADIOMETRIC EAR AS SAY

From Fig. 4 it can be seen that in unsensitised rats (column A) and in rats sensitised with ICFA (column 


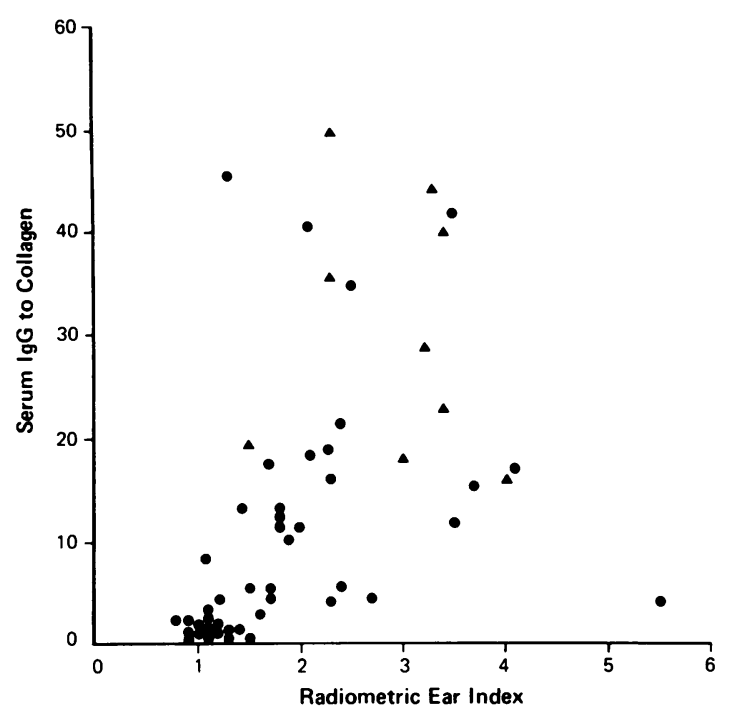

Fig. 5 Comparison of serum levels of antibody to native type II collagen with the radiometric ear index to native type II collagen in 53 rats.

B) or CFA (column C) emulsified with $0.45 \mathrm{M}$ $\mathrm{NaCl} / 0.02 \mathrm{M}$ Tris an ear ratio of 1.6 or less was obtained when the rats were challenged with native bovine type II collagen 21 days after immunisation.

In 5 rats sensitised to native type II collagen +ICFA the ear ratios were between $1 \cdot 1$ and 1.4 when challenged with native type I collagen (column D) 21 days after immunisation. This group included an arthritic rat which had a ratio of $1 \cdot 1$. These findings suggest that these ratios of 1.6 and below are nonspecific responses.

A group of 20 Sprague-Dawley rats immunised 10 days previously with native bovine type II collagen gave ear ratios between 0.7 and 3.5 (median 1.4 ), (fig. 4, column E). This was before any clinical signs of arthritis.

When a group of 84 rats (Sprague-Dawley) immunised with native type II collagen in ICFA 19-21 days previously were challenged with native type II collagen in the ear assay, ratios between 0.8 and 5.5 (median 1.4 ) were obtained for the 67 clinically nonarthritic rats and $1 \cdot 5-6 \cdot 9$ (median $3 \cdot 2)$ for the 17 arthritic rats (Fig. 4, columns $F$ and $G$ ). These groups were statistically significantly different by the Mann-Whitney U test $(p<0 \cdot 001)$.

In 54 of these rats ( 10 arthritic, 44 nonarthritic) the serum IgG levels to native type II collagen were measured on days $20-21$ and are shown in Fig. 5 plotted against the ear responses. There was a tendency for arthritic rats to have both a high ear ratio

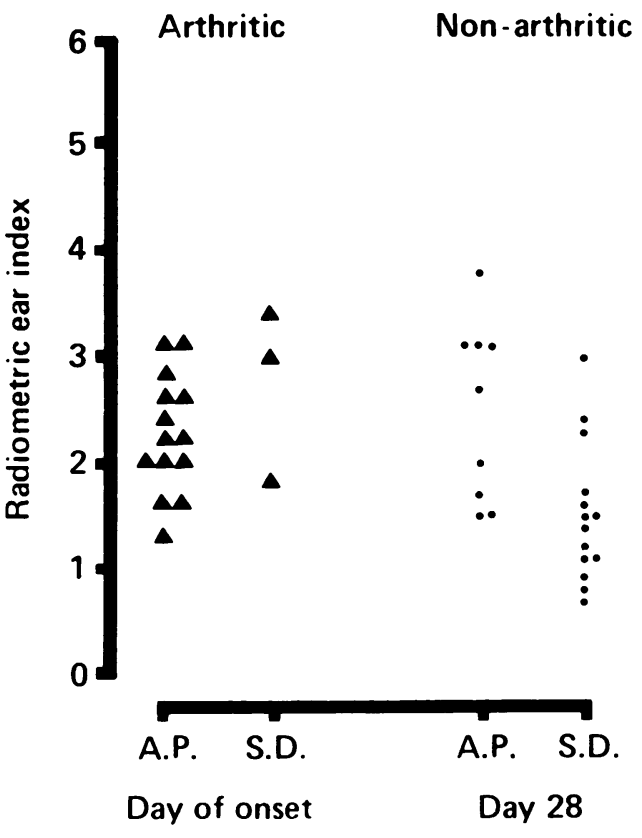

Fig. 6 Radiometric ear assay: levels in Alderley Park $(A P)$ and Sprague-Dawley $(S D)$ rats.

and high antibody levels, though some rats which did not develop clinical arthritis also had similar levels. However, there was no statistically significant correlation between ear ratios and the anticollagen antibody level in arthritic rats, but there was a correlation in nonarthritic rats $(\mathrm{p}<0 \cdot 001)$.

A group of 10 Alderley Park rats immunised with ICFA emulsified with buffer 21 days previously and challenged with native bovine type II collagen in the ear assay gave ratios between 0.6 and 1.4 (median 1.05 . These were similar ratios to those found in Sprague-Dawley rats immunised in the same manner.

A group of 17 Sprague-Dawley rats and 23 Alderley Park rats were immunised with native bovine type II collagen, and the radiometric ear index was measured on the day of onset of arthritis and on day 28 in those rats which were nonarthritic. Three of the $17(17 \cdot 6 \%)$ Sprague-Dawley rats and 14 of the 23 (60.9\%) Alderley Park rats developed an inflammatory arthritis. Ear indices for rats on the day of onset of arthritis were between 1.3 and 3.1 (median $2 \cdot 2$ ) for Alderley Park rats and 1.8-3.4 (median 3.0) for the Sprague-Dawley rats (Fig. 6). For nonarthritic rats the ratios were between 1.5 and 3.8 (median $2 \cdot 4$ ) for the Alderley Park rats and between 0.7 and 3.0 (median 1.45) for the Sprague-Dawley rats. Thus similar ear ratios were obtained with each group 
although the Alderley Park strain proved more susceptible to developing arthritis), and one Alderley Park rat had an ear ratio at the background level on the day of onset of arthritis.

\section{Discussion}

Then in-vitro stimulation of lymphocytes by antigen, a $\mathrm{T}$ lymphocyte function, ${ }^{16}$ was applied to rats immunised with native type II collagen. We have demonstrated that the response was antigen specific and that lymphocytes from rats immunised with native type II collagen gave similar responses in-vitro whether the collagen had been emulsified in ICFA or CFA and whether the rats developed arthritis or not. Thus among arthritic rats some had lymphocytes which failed to respond at all to collagen in-vitro despite their continued viability and their ability to respond to con-A, a known T-cell mitogen. ${ }^{17}$ Nonarthritic rats showed a similar spectrum of response when their lymphocytes were tested. These findings suggest that a T-cell-mediated response is not essential for the induction of the arthritis. However, it may be important in determining whether the arthritis becomes chronic or not, as Trentham et al. ${ }^{3}$ described a higher in-vitro stimulation response to collagen in peripheral blood mononuclear cells from rats with chronic polyarthritis than in nonarthritic rats immunised 42-70 days earlier. Our findings are in disagreement with those of Stuart et al ., ${ }^{4}$ who showed a higher stimulation of collagen of peripheral blood, spleen, and lymph node lymphocytes from athritic rats immunised 14-28 days previously. In their rats the response in nonarthritic animals declined after day 14 but remained elevated in arthritic animals. Whether these differences are due to the strain of rat used, the type of collagen used for immunisation, the culture conditions, or the presence or absence of antigen-specific suppressor cells remains unclear at present.

The radiometric ear assay was used as a measure of the accumulation of radioactively labelled cells at the site of antigen challange. We have shown the assay to be specific in that high indices were obtained only by a challenge with native type II collagen in rats immunised with native type II collagen. The majority of arthritic rats gave high indices, while the majority of nonarthritic rats gave levels similar to the control groups, and this difference was statistically significant. However, a few arthritic rats gave indices at the control levels even on the day of onset of arthritis, and some nonarthritic rats had high ear indices equivalent to those found in arthritic rats. The radiometric ear assay is said to be a measure of delayed-type hypersensitivity, a T-cell-dependent delayed response. ${ }^{18}$ As some arthritic rats had ear indices at the control levels even on the day of onset of arthritis, this response may not be important in the induction of the arthritis but again may play a role in determining whether the arthritis becomes chronic or not.

There was no correlation between the serum levels of IgG antibody to native bovine type II collagen and the in-vitro lymphocyte stimulation index in immunised rats whether they were arthritic or not. All the rats had some serum antibody to collagen but not all responded in the in-vitro lymphocyte stimulation assay. The arthritic rats tended to have high levels of antibody to native type II collagen in their serum, suggesting that the antibodies might be important in the arthritis, although some nonarthritic rats also had high levels of antibody.

There was no correlation between the serum levels of IgG antibody to native type II collagen and the radiometric ear indices in arthritic rats, but there was in nonarthritic rats. Again all arthritic rats had high levels of antibodies.

Thus the in-vitro test for cell mediated immunity (CMI) suggested that CMI to collagen may not be important in initiating the arthritis, though its part in prolonging the response is unresolved. The in-vivo test was equivocal, in that, while most arthritic rats had higher ear ratios than nonarthritic rats, some had no response on the day of onset of arthritis. However, all the rats which were arthritic had serum IgG antibodies to native type II collagen, and this finding is in agreement with previous reports. ${ }^{3-5}$ Thus antibodies to collagen seem to play a more predominant role in the initiation of the arthritis. This role for antibody is supported by the apparent necessity for complement in the induction of this arthritis ${ }^{8}$ and by the demonstration of the passive transfer of arthritis to naive rats by antibody alone. ${ }^{7}$ Other predisposing factors may also be necessary, since some rats can produce this immune response to collagen without signs of clinical arthritis.

We are grateful to Miss Jacqueline Weiss for analysis of the collagen types and for advice on their preparation. We thank the Faculty of Medicine Computational Group for statistical advice, Mrs Doreen Ward for typing the manuscript, and the Department of Medical Illustration for preparing the figures. We are indebted to Drs M. Billingham and M. Smith for the Alderley Park rats.

The work was supported by grant from the Arthritis and Rheumatism Council for Research and the North Western Regional Hospital Board.

\section{References}

1 Trentham D E, Townes A S, Kang A H. Autoimmunity to type II collagen: an experimental model of arthritis. $J$ Exp Med 1977; 146: 857-67.

2 Courtney J S, Dallman M J, Dayan A D, Martin A, Mosedale B. Immunisation against heterologous type II collagen induces arthritis in mice. Nature 1980; 283: 666-8. 
3 Trentham D E, Townes A S, Kang A H , David J R. Humoral and cellular sensitivity to collagen in type II collagen-induced arthritis in rats. J Clin Invest 1978; 61: 89-96.

4 Stuart J M, Cremer M A, Kang A H, Townes A S. Collagen-induced arthritis in rats: evaluation of early immunological events. Arthritis Rheum 1979; 22: 1344-51.

5 Morgan K, Clague R B, Shaw M J, Holt P J L. Native type II collagen-induced arthritis in the rat. I. Incidence and humoral response to collagen. Ann Rheum Dis 1980; 39: 285-90.

6 Trentham D E, Dynesius R A, David J R. Passive transfer by cells of type II collagen-induced arthritis in rats. $J$ Clin Invest 1978: 62: 359-66.

7 Stuart J M, Cremer M A. Townes A A, Kang A H. Type II collagen-induced arthritis in rats. Passive transfer with serum and evidence that IgG anticollagen antibodies can cause arthritis. J Exp Med 1982; 155: 1-16.

8 Morgan K, Clague R B, Shaw M J, Firth S A, Twose T M, Holt $P$ J L. Native type II collagen-induced arthritis in the rat. The effect of complement depletion by cobra venom factor. Arthritis Rheum 1981; 24: 1356-62.

9 Clague R B, Morgan K, Shaw M J, Holt P J L. Native type II collagen-induced arthritis in the rat. 2. Relationship between the humoral immune response to native type II collagen and arthritis. J Rheumotol 1980; 7: 775-82.

10 Trelstad R L, Rubin D, Gross J. Osteogenesis imperfecta congenita: evidence for a generalised molecular disorder of collagen. Lab Invest 1977; 36: 501-8.

11 Jackson D S, Cleary E G. In: Glick D, ed. Methods of Biochemical Analysis. New York: Interscience Publishers, 1967; 15: 32-3.

12 Bitter T, Muir H M. A modified uronic acid carbazole reaction. Anal Biochem 1962; 4: 330-4.

13 Ramasamy $\mathbf{R}$. A flourescent stain for viable rosette-forming cells. J Immunol Methods 1974; 5: 305.

14 Gans K R, Heyner S, Orzechowski R F. Application of a radiometric ear assay for studies of adjuvant arthritis in rats. Arthritis Rheum 1980; 23: 633-40.

15 Clague R B, Brown R A, Weiss J B, Holt P J L. Solid-phase radioimmunoassay for the detection of antibodies to collagen. J Immunol Methods 1979; 27: 31-41.

16 Corradin G, Etlinger H M, Chiller J M. Lymphocyte specificity to protein antigens. I. Characterisation of the antigen-induced in vitro $T$ cell-dependent proliferative response with lymph node cells from primed mice. J Immunol 1977; 119: 1048-53.

17 Greaves M F, Janossy G. Elicitation of selective T and B lymphocyte responses by cell surface binding ligands. Transplant Rev 1972; 11: 87-130.

18 Kostiala A A I. Radiometric ear index test as a measure of delayed-type hypersensitivity in the rat. Immunology 1977; 33: 561-71. 